\title{
EL COLEGIO DEL ESTADO DE PUEBLA Y SUS DOCUMENTOS FUNDACIONALES
}

Por María de Lourdes Herrera Feria y Rosario Torres Domínguez con la colaboración de Edgar Iván Mondragón Aguilera. Puebla: BUAP- Biblioteca José María Lafragua, 2017, 279 págs. ISBN: 978-607-525-423-4

La historiografía sobre la educación del siglo XIX en México, en particular sobre el tránsito que significó la reconfiguración de universidades y colegios de corporaciones que eran a establecimientos de instrucción pública, ha aumentado considerablemente en los últimos años, ${ }^{1} \sin$ embargo, aún quedan muchos huecos por llenar, preguntas que resolver, fuentes que descubrir o releer. En este sentido, un libro que ofrece la transcripción de los documentos fundacionales del Colegio del estado de Puebla de 1825 a 1867, de la autoría de María de Lourdes Herrera y Rosario Torres, es siempre bienvenido. A la transcripción de constituciones, estatutos y reglamentos, las autoras añaden un estudio centrado en explicar los antecedentes novohispanos del colegio.

Como ha mostrado la historiografía, la educación pública media superior y superior como hoy la conocemos, tuvo una de las etapas claves en su proceso de desarrollo en el lapso del último tercio del siglo XVIII a varias décadas del XIX, cuando transitó paulatinamente de un modelo educativo basado en corporaciones y fuerte influencia religiosa a otro que conformaría un sistema laico, jerarquico y homogéneo de instrucción pública. En otras palabras, se pasó de un modelo de colegios ligados

\footnotetext{
${ }^{1}$ Susana Quintanilla, «Historiografía de la educación superior en México, siglos XIX y XX», en La educación superior en México: historiografía y fuentes, eds. Óscar García y Sonia Ibarra (Guadalajara: El Colegio de Jalisco y el Centro Universitario de Ciencias Sociales y Humanidades de la Universidad de Guadalajara, 2003), 205-230; Rosalina Ríos Zúñiga, «La historiografía de inicios del siglo XXI sobre la educación "media y superior" del siglo XIX», en Historia e historiografía de la educación en México. Hacia un balance, 2002-2011, coord. $\mathrm{M}^{\mathrm{a}}$ Esther Aguirre Lora (México: Asociación Nacional de Universidades, Institutos de Educación Superior-Consejo Mexicano de Investigación Educativa, 2016), 225-229.
} 
a una lejana universidad que otorgaba los grados —o cercana según la distancia-, a otro en el que cada estado del México independiente contaría con una institución que podría ofrecer enseñanza universitaria y otorgar por si misma los grados y títulos. Muchas otras implicaciones tendría esto, pues el mundo escolar no consistía solo en lo institucional, sino sobre todo en lo social, que abarcaba una gran cantidad de actores, entre ellos rectores, vicerectores, mayordomos, profesores, y alumnos, becados o pensionistas; así como otros elementos que permitían - permiten- el funcionamiento de las instituciones educativas, como son las cátedras o saberes y el financiamiento. Cada aspecto a su vez conteniendo su propia problemática sin dejar de estar interrelacionados entre si.

El libro, que se presenta en una edición de lujo con numerosas imágenes, está dividido en cuatro partes: la primera ofrece lo que toda buena transcripción debe hacer, como lo es exponer las normas que guiaron esa labor, la definición del concepto constitución y detalles que se procuraron, entre ellas indicar la modernización en la ortografía de las palabras.

La segunda presenta la interpretación que hacen las autoras de la historia del Colegio de Puebla, desde sus antecedentes jesuitas hasta 1867. Así conocemos los cinco colegios que funcionaban en Puebla: el del Espíritu Santo, el de San Ildefonso donde se tomaban los cursos, el de San Gerónimo y el de San Ignacio, que funcionaban como residencias para los estudiantes; y el de San Francisco Xavier que servía como colegio de indios, hasta la expulsión de la orden de San Ignacio en 1767. Se echa de menos una problematización sobre el carácter que tenía cada uno de dichos colegios sobre lo que puede dialogarse con autores como Víctor Gutiérrez o Mónica Hidalgo, ${ }^{2}$ especialistas en colegios coloniales novohispanos; no obstante, las autoras repasan paso a paso las diversas vicisitudes que padecieron esos colegios para ser reabiertos, si bien con funciones distintas a las que se les habían destinado inicialmente, y revisan cómo hacía 1790 se fundieron dos de ellos (San Gerónimo y San Ignacio) en uno sólo, quedando únicamente el del Espíritu Santo que

\footnotetext{
2 Víctor Gutiérrez Rodríguez, «Hacía una tipología de los colegios coloniales», en De maestros y discípulos: México, siglos XVI a XIX, coord. Leticia Pérez Puente (México: Centro de Estudios sobre la Universidad, 1998), 81-90. Mónica Hidalgo Pego, Reformismo Borbónico y educación. El Colegio de San Ildefonso y sus colegiales 1768-1816 (México: Instituto de Investigaciones sobre la Universidad y la Educación-UNAM, 2008).
} 
poco después fue nombrado como Colegio Carolino en honor a Carlos III, quedando bajo la administración de la Diócesis Poblana y bajo el Patronato Real, disponiéndose en este de todo lo concerniente para su buen funcionamiento. Posteriormente, se explica que, en 1820, con el retorno de los jesuitas, gracia que le fue otorgada a la orden por Fernando VII en 1815, culminó su etapa como Colegio Carolino, renombrándosele como Colegio del Espíritu Santo, de San Ignacio y San Gerónimo. Esta etapa, sin embargo, fue brevísima debido a la nueva expulsión de la Orden, en 1821.

La parte más importante para el estudio, viene a ser la que las autoras llaman la administración civil del Colegio del Estado de Puebla, que transcurre de 1824 a 1867. La intención de las autoras fue responder a las siguientes preguntas: ¿Cómo transcurre en ese tiempo el desarrollo institucional del Colegio del estado, cuánto cambia, cuánto permanece? Las autoras nos dicen que, inicialmente parece no cambiar casi nada. Sus primeros cinco años, pese a los esfuerzos e interes mostrados por las nuevas autoridades, mantuvieron las prácticas de origen colonial. Fue a partir de 1825, una vez otorgada la autorización del Congreso al gobernador para que se hiciera cargo de la institución, que se tomaron cartas en el asunto, y el colegio pasó a depender del gobierno estatal. Sin embargo, las constituciones que se redactan en 1826 únicamente copian las que se habían elaborado a fines del siglo XVIII.

En 1831, continuan las autoras, se escriben otras constituciones, en las que se retoma para el colegio parte del antiguo nombre: Antiguo y muy Ilustre Colegio de San Gerónimo y San Ignacio del estado de Puebla. En esas constituciones apenas se advierten algunos leves cambios, como el hecho de que las autoridades del colegio estarían obligadas a consultar todo lo relativo a los asuntos internos con las autoridades del estado.

El siguiente paso, y contra lo que siempre ha interpretado la historiografía, los aires de la reforma educativa liberal de 1833 de Valentín Gómez Farías y José María Luis Mora, ${ }^{3}$ que únicamente se enfocaban al

\footnotetext{
3 Valentín Gómez Farías y José María Luis Mora fueron políticos mexicanos de orientación liberal, participantes en el régimen del militar Antonio López de Santa Anna de 1833 a 1834. Bajo la conducción del primero como vicepresidente y el apoyo del segundo, llevaron adelante una reforma educativa liberal que suprimió la antigua universidad y los colegios, además de abrir seis establecimientos
} 
Distrito Federal y los territorios, por la vigencia del régimen de gobierno federal, tocaron también a Puebla, pues en 1834 las autoridades propusieron tanto un nuevo plan de estudios y nuevas constituciones para el colegio. No obstante, como ocurrió en la Ciudad de México, las medidas no fueron aceptadas del todo por la sociedad poblana.

Para las autoras, la pregunta pendiente seguía siendo ¿Cuándo llegaron los tiempos «modernos» al Colegio del estado de Puebla? Es decir, cuando comenzó realmente a transitar hacia otro modelo educativo acorde con los nuevos tiempos. Ellas ubican ese momento hacia el inicio de la década de 1840, comenzando por un detalle cotidiano: el desuso del tradicional traje talar, tan habitual en ese tipo de instituciones. También la influencia de otra reforma: la que encabezó el ministro de Justicia, Negocios Eclesiásticos e Instrucción Pública en 1843, Manuel Baranda $^{4}$ —al que por cierto no mencionan-, que tuvo un carácter nacional y centralizador. Las medidas que propusó tocaron las puertas de las autoridades de Puebla y llevaron a que se emprendieran cambios en su colegio, sobre todo en lo referente a la enseñanza secundaria, pues se agregaron por ejemplo, nuevas cátedras, como fueron el idioma castellano y el curso de ideología, que aumentaron años a los estudios. Modificaciones que, como sucedió en otros lugares, alarmaron a los padres de familia, pues estos pensaron que llevarían a una estadía más larga de sus hijos en el Colegio. Además, durante toda la década de los 1840 ocurrieron otros cambios, tanto de nombre de las cátedras como adecuaciones de otro carácter, que fueron resquebrajando el antiguo modelo educativo.

Una década después, habría más transformaciones con otra reforma educativa, la del magistrado Teodosio Lares. ${ }^{5}$ Esa reforma, puesta

educativos para los estudios preparatorios y profesionales, además de organizar una Dirección General de Estudios y un financiamiento público de la educación con base principalmente en propiedades y rentas de las antiguas corporaciones educativas y religiosas. Duró únicamente 10 meses, pues se derogó en 1834 .

${ }^{4}$ Abogado originario del estado de Guanajuato, considerado liberal moderado, fue nombrado ministro de Justicia, Negocios Eclesiásticos e Instrucción Pública durante un gobierno centralista en 1842. Impulsó una importante reforma educativa, la primera de carácter nacional.

${ }^{5}$ Abogado originario del estado de Zacatecas, fue ministro de Justicia, Negocios Eclesiásticos e Instrucción Pública del último gobierno de Antonio López de Santa Anna (1853-1855), elaboró las Lecciones de Derecho Administrativo en 1852 y posteriormente participó con el grupo que apoyó la llegada y gobierno de Maximiliano de Habsburgo (1864-1867). 
en práctica en 1854, le dio un carácter más jerárquico a los niveles de estudios y aumentó el número de años a cursar, entre otros aspectos. Las críticas y desacuerdos sobre tales cambios, sobre todo, por la prerrrogativa de los poderes públicos sobre la institución, la centralización que imponía, la restauración de la universidad, la preferencia por la educación secundaria o preparatoria y profesional sobre la primaria, no se dejaron esperar. No obstante, el triunfo del conocido en la historia de México como Plan de Ayutla, que derribó el gobierno dictatorial de Santa Anna en 1855, llevó a la derogación de ese proyecto educativo y a detener el avance modernizador que se pretendía en la instrucción pública.

Las autoras continúan analizando los nuevos conflictos y situaciones que en los años subsecuentes llevaron a nuevos cambios en el colegio poblano; por ejemplo, la llegada al poder de otro gobierno liberal que lo renombra como Colegio Nacional del Espíritu Santo; posteriormente el gobierno Imperial de Maximiliano, en 1864, le dará el de Colegio imperial, situaciones bien apuntadas por las autoras. Más importante fue que, en esta última etapa se pretendió por el emperador que se fomentara otro tipo de escuelas más de carácter científico y filosófico o que se proyectara la educación física de los jóvenes. Habría una división de los estudios superiores en dos ramas: una orientada a la carrera literaria y otra a una profesión más práctica. Debido a sus condiciones, no obstante, suspendió sus actividades, tanto para repararlo como para que a su apertura estuviera dispuesto para la nueva orientación. El rescate más importante que hacen las autoras, dado el objetivo e interes que persiguen, es el de las constituciones que se utilizaron en ese momento, pues fueron las de 1842, a las que únicamente se les agregó la palabra Imperial. Después, este adjetivo sólo se tacharía en el documento para darle nuevamente uso. En suma, encuentran que las constituciones reelaboradas en 1842 fueron normas que rigieron hasta el periodo del Imperio de Maximiliano (1864-1867).

La última etapa analizada por las autoras en este apartado es la del llamado por la historiografía mexicana como del triunfo liberal, en 1867, cuando nuevas y definitivas transformaciones fueron propuestas para el colegio, al que volvió a dársele el nombre de Colegio del Estado. El rector del colegio presentó en octubre de ese año un nuevo reglamento que sería puesto en práctica, en tanto se obtenía la aprobación del Congreso del 
Estado. Se decía en ese documento que los candidatos a pertenecer a la institución debían "pertenecer al estado secular y mostrar un Amor comprobado con hechos a las instituciones republicanas» y debían guardar respeto a leyes, reglamentos e instituciones de «los Estados unidos mexicanos» (p. 97). Es decir, comenzaba realmente el periodo de la educación pública laica.

A partir de ese año quedó dividida la educación del estado en los niveles de primaria, secundaria, profesional y estudios especiales. Comenzó así otro momento en el proceso de construcción de un sistema de instrucción pública, como sucedió en todo el país, y en particular en el modelo de colegios y escuelas nacionales de enseñanza secundaria o preparatoria y profesional.

La tercera parte del libro nos ofrece la cuidadosa transcripción de las constituciones, estatutos y reglamentos u otros documentos relativos al Colegio del Estado. Sorprenden ciertamente los pocos cambios que se van haciendo notar en los documentos entre 1824 y 1842, pues la mayor parte de prácticas parecen las mismas. Sobre todo, que se retomaron constituciones anteriores para ponerlas en un documento que se pretendió pasar por nuevo. No así con el gran cambio que se observa en 1867, en el que se presentaron las nuevas constituciones del Colegio, las que, antes de ser aprobadas por el Congreso pasaron por una revisión cuidadosa que corrigió fallas garrafales como agregar que no solamente se trataba de educación secundaria, sino también la superior. Además de otros detalles aparentemente menores pero que podían terminar siendo graves.

Finalmente, el cuarto apartado, ofrece la reproducción de los documentos originales, para que quien quiera hacer su propia transcripción o cotejar la que cuidadosamente hicieron las autoras de la presente obra, esté en posibilidad de hacerlo.

En suma, el libro Los documentos fundacionales del Colegio del estado de Puebla es de suma valía, por la interpretación que realizan Herrera y Torres acerca de la historia del mencionado colegio desde fines del siglo XVIII hasta 1867 con base en los documentos transcritos y su conocimiento de la historia de la educación de Puebla. Si bien puede señalarse que no ahondan en las problemáticas que conllevó transitar de las corporaciones de 
antiguo regimen a las instituciones de educación pública, o a comparaciones de estas con lo que pasaba en el resto del territorio primero novohispano, después nacional e incluso hispanoamericano, ${ }^{6}$ así como se extraña que no establezcan un diálogo más amplio con la historiografía existente sobre el tema. No cabe duda de que trabajos como este ofrecen una gran oportunidad a los interesados en desentrañar el complejo proceso de construcción y tránsito de una antigua a una nueva enseñanza en el siglo XIX, pues si algo se hace necesario es acudir a las fuentes originales, no siempre al alcance de la mano. Por eso, este tipo de esfuerzo de transcripción tan cuidadoso y bien hecho no puede menos que aplaudirse. Contamos pues con este valioso material - sobre todo las constituciones-, como base para futuras indagaciones en las que se privilegie como segundo paso, investigar como fue la puesta en práctica de la legislación. Es decir, cuál fue la realidad de su aplicación.

Rosalina Ríos Zúñiga Universidad Nacional Autónoma de México rorst5@hotmail.com

\footnotetext{
6 Dorothy Tanck de Estrada, «La ciudad durante tres regímenes, 1768-1838», en Historia de la educación en la ciudad de México, coords. Pilar Gonzalbo Aizpuru y Anne Staples (México: Colmex/Secretaria de Educación del Distrito Federal, 2012), 117-174. Enrique González González, Por una historia social de las universidades de la América Hispana en el periodo colonial (México: IISUE-UNAM, Benemérita Univaersidad Autónoma de Puebla, UAM, Ediciones de Educación y Cultura, 2017). Anne Staples, «La educación después de las reformas de 1833», en Masonería y sociedades secretas en México, coords. José Luis Soberanes Fernández y Carlos Francisco Martínez Moreno (México: UNAM-Instituto de Investigaciones Jurídicas, 2018),385-400.
} 